\title{
Bestimmung von CDT (Carbohydrate Deficient Transferrin), $\gamma$-GT, Methanol, Isopropanol und Ethanol in forensischen Blutproben zur Beurteilung chronischen Alkoholmißbrauchs
}

\author{
Determination of CDT (Carbohydrate Deficient Transferrin), $\gamma$-GT, methanol, \\ isopropanol and ethanol in forensic blood samples for assessment of \\ chronic alcohol abuse
}

T. Gilg', S. Weidinger ${ }^{2}$, E. Josephi', Edith Tutsch-Bauer', L. von Meyer', W.P. Bieger ${ }^{2}$

Institut für Rechtsmedizin der Ludwig-Maximilians-Universität München'

Medizinisch Immunologische Laboratorien, München ${ }^{2}$

\section{Zusammenfassung:}

In 64 forensischen Blutproben wurden prospektiv Alkoholismusmarker bzw. Indikatoren für Alkoholmißbrauch wie Blutalkoholkonzentration (BAK), Carbohydrate Deficient Transferrin (CDT), Serummethanol (SMK), Isopropanol und $\gamma$-GT bestimmt. Bei den untersuchten Personen handelt es sich ausschließlich um Männer und Frauen mit unbekannter Alkoholanamnese, die Straftaten unter Alkoholeinfluß begingen.

Die Analyse von CDT mit der hochauflösenden isoelektrischen Fokussierung ergab regelmäßig deutliche Bandenmuster, wenn mehr als $20 \mathrm{U} / \mathrm{l}$ im quantitativen CDTect ${ }^{\mathrm{MM}}$ feststellbar waren. Insgesamt fanden sich Normwerterhöhungen bei CDT in 59\%, BAK $(>1,6 \%$ ) in $52 \%$, SMK in $23 \%$ (bei BAK $>2 \%$ in $63 \%$ ), Isopropanol in $47 \%$ und $\gamma-G T$ in $63 \%$ der Fälle. Das Fehlen von korrelativen Zusammenhängen zwischen den einzelnen Parametern kann durch die unterschiedliche Pathogenese und verschiedene Alkoholbelastungsmuster erklärt werden. Jeder Parameter für sich kann als Hinweis für Alkoholmißbrauch angesehen werden; durch Kombination kann die diagnostische Effizienz und Sicherheit verbessert werden.

Für CDT wird eine hohe Spezifität bis zu $100 \%$ beim Nachweis von Alkoholabusus angegeben, bei Normwerten von 20 U/I für Männer bzw. 26 U/I für Frauen. Unter forensischen Kriterien wäre zur Diagnose eines Alkoholmißbrauchs eher ein Grenzwert von $30 \mathrm{U} / \mathrm{l}$ realistisch bzw. sind andere Parameter für eine sicherere Beurteilung mit heranzuziehen.

\section{Schlüsse/wörter:}

Carbohydrate Deficient Transferrin-Gamma-Glutamyl-Transferase-Ethanol-Alkoholmißbrauch - Alkoholismusindikatoren

\section{Summary:}

Markers or indicators for alcohol abuse such as blood alcohol concentration (BAC), Carbohydrate Deficient Transferrin (CDT), serum methanol (SMC), isopropanol and $\gamma$ GT were determined prospectively in 64 forensic blood samples of men and women alleged to have committed crimes under the influence of alcohol,but with unknown alcohol anamnesis. The analysis of CDT of high resolving isoelectric focusing gave distinct band patterns, if more than $20 \mathrm{U} / \mathrm{I}$ were detectable by quantitative CDTect ${ }^{\mathrm{TM}}$. Abnormally elevated levels of CDT were found in $59 \%$, of BAC (>1,6\%) in $52 \%$, SMC in $23 \%(63 \%$ with BAC>2\%o), isopropanol in $47 \%$ and $\gamma-G T$ in $63 \%$ of cases. Correlations between the mentioned parameters were not found, which can be explained by different pathogenesis and different patterns of alcohol intake. Each single parameter can be taken as a hint for alcohol abuse; diagnostic efficiency and reliability can be improved by a combination. Regarding CDT, a high specifity of up to $100 \%$ is cited for detecting alcohol abuse, with normal upper limits of $20 \mathrm{U} / \mathrm{l}$ in men and $26 \mathrm{U} / \mathrm{I}$ in women. For diagnosis of alcohol abuse under forensic criteria, a limit of $30 \mathrm{U/I}$ would be more realistic or other parameters should be considered for a more reliable assessment. 


\title{
Originalie
}

\author{
Keywords: \\ Carbohydrate Deficient Transferrin - gamma-glutamyl transferase, - ethanol-alcohol \\ abuse - alcoholism indicators
}

\section{Einleitung}

Übermäßiger oder exzessiver Alkoholkonsum führt als biologischer und vor allem biochemischer Einflußfaktor bekanntermaßen zu Veränderungen zahlreicher klinischchemischer Parameter. Diese spielen bei den meisten Diagnoseschemata für Alkoholmißbrauch oder Alkoholabhängigkeit/Alkoholismus, wie z.B. MALT (Münchner Alkoholismus Test) (12), CAGE Questionnaire (5) oder ICD 10 (International Classification of Diseases) und DSM IV (Diagnostic and Statistical Manual of mental disorders), eine zentrale Rolle. Neben klinischen und differentialdiagnostischen Aspekten sind derartige Alkoholismusmarker insbesondere für Screening-Untersuchungen in der Arbeits-, Verkehrs- und Rechtsmedizin wie auch für Verlaufskontrollen nach Alkoholentzug von Bedeutung. Sensitivität und Spezifität nahezu aller bekannten Marker für Alkoholmißbrauch, Alkoholismus oder alkoholische Organschäden variieren z.T. beträchtlich. Einflußfaktoren sind beispielsweise nicht-alkoholbedingte Erkrankungen, enzymstimulierende Medikamente, Fehl/Mangelernährung, metabolische Störungen, Alter, Nikotin u.a.

Unter den zahlreichen alkoholassoziierten Veränderungen von Laborparametern wird vor allem $\gamma$-GT und MCV eine höhere Spezifität und Sensitivität zugeschrieben (4, $12,16,20-23,53,54,72,76,77)$. Ferner spielen HDL-Cholesterin und Apolipoprotein (8-11) sowie insbesondere CDT zunehmend eine größere Rolle.

$\gamma$-Glutamyl-Transferase transferiert als mitochondriales Enzym $\gamma$-Glutamylgruppen auf Aminosäuren und spaltet Glutathion in Glutamat und Cysteinylglycin. Nach weiterer Peptidasespaltung in Cystein und Glycin kann durch $\gamma$-GT- und Glutathionsynthetase wieder Glutathion gebildet werden.

Zahlreiche Studien bestätigen die klinische Bedeutung vor allem isoliert erhöhter Serumspiegel als "Leitenzym" für Screening und Diagnose von Alkoholmißbrauch oder Alkoholismus $(4,5,21-23,53,54)$.

\section{Abkürzungen:}

$\begin{array}{ll}\text { ADH } & =\text { Alkoholdehydrogenase } \\ \text { BAK } & =\text { Blutalkoholkonzentration } \\ \text { CHE } & =\text { Cholinesterase } \\ \text { GOT } & =\text { Glutamat-Oxalacetattransaminase } \\ \text { GPT } & =\text { Glutamat-Pyruvattransaminase } \\ \text { HWZ } & =\text { Halbwertszeit } \\ \text { IEF } & =\text { Isoelektrofokussierung } \\ \text { MCV } & =\text { Mittleres corpuskuläres Erythrozytenvolumen } \\ \text { MEOS } & =\text { Mikrosomales ethanoloxidierendes System } \\ \text { NAD(H) } & =\text { Nikotinamidadenindinukleotid(-H) } \\ \text { SMK } & =\text { Serummethanolkonzentration } \\ \text { Sensitivität } & \text { Prozentualer Anteil positiver Befunde bei Alkoholi- } \\ & \text { kern } \\ \text { Spezifität } & =\text { Prozentualer Anteil negativer Befunde bei Nicht- } \\ & \end{array}$

Freisetzung und erhöhte Serumspiegel sind in erster Linie Ausdruck einer Enzyminduktion und weniger einer Leberzellschädigung, weshalb Erhöhungen auch durch Medikamente wie z.B. Phenobarbital und allgemeine xenobiotische Stoffwechselbelastung (u.a. Nikotin) beschrieben sind. Jeder $\gamma$-GT-Anstieg ist jedoch Zeichen einer Leberschädigung, wenn leberspezifische Enzyme wie GOT, GPT, GLDH oder CHE ebenfalls pathologisch sind (77). Insofern sind Sensitivität (etwa 50-90\%) und Spezifität $(60-79 \%)$ zwar hoch, jedoch als alleiniger Parameter nicht ausreichend $(4,22,23,33,53,54)$.

Kurzzeitige, auch höhere Alkoholbelastung führt .zwar teilweise zu geringen Anstiegen, jedoch nicht zum Überschreiten von Normalwerten von $\gamma$-GT (oder GOT, GPT, GLDH) $(21-23,43)$.

Nach Alkoholentzug ist mit einer Normalisierung nach ca. 2-3 Wochen bis zu 60 Tagen (HWZ ca. 26 Tagen) zu rechnen. Ca. 2 Wochen nach erneutem Alkoholmißbrauch resultieren wieder abnorm erhöhte Werte (16, 21-23).

Erhöhungen der Serumaktivität von GOT, GPT und GLDH sind dagegen bereits Ausdruckeiner auch unspezifischen hepatozellulären Schädigung, deren alkoholtoxische Ursache erst durch andere klinische und chemische Parameter sowie diagnostische und anamnestische Maßnahmen zu klären ist.

MCV: Die Bestimmung des mittleren, corpuskulären Erythrozytenvolumens gehört zu den einfachen, aber auch hochspezifischen (76-95\%), jedoch geringer sensitiven (25-91\%) Methoden $(4,8,23,53,54,76,77)$.

Als Ursache der Makrozytose mit charakteristischen Erhöhungen über $96 \mathrm{~mm}^{3}$ bzw. fl, je nach Methodik auch >92 oder >100, wird eine alkoholtoxische Knochenmarkschädigung angenommen, unabhängig von Folsäurestatus oder Folsäuretherapie. Auch chronische Strukturveränderungen des Hämoglobins durch Acetaldehydanlagerung-hämoglobinassoziierter Acetaldehyd (HAA),

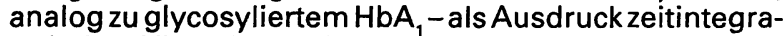
ler hoher Alkohol/Acetaldehydbelastung über die Erythrozytenlebensdauer werden diskutiert (51). Hierfür spricht die Normalisierung erst ca. 2-3 Monate nach Aikoholentzug analog der Erythrozytenlebensdauer. Dieser Resistenz gegenüber kurz- und mittelfristiger Alkoholkarenz kommt besonderer Aussagewert bei Begutachtungsfragen zu, wie z.B. bei der Wiedererteilung einer Fahrerlaubnis nach Trunkenheitsdelikten im Straßenverkehr $(4,8,22,23)$.

Da die Bestimmung jedoch frische und nicht gelagerte bzw. hämolytische Blutproben erfordert, ist sie im forensischen Routinebereich kaum realisierbar.

Erwähnenswert sind auch HDL-Cholesterin und Apolipoprotein, da sie weitgehend ernährungsunabhängig reagieren und wie CDT als hochspezifisch und sensitiv für chronische Alkoholbelastung angesehen werden. Als 
Ursache wird u.a. eine erhöhte Lipoproteinlipaseaktivität und ein Zusammenhang mit alkoholbedingter Enzyminduktion bei Konkordanz mit MEOS und $\gamma$-GT diskutiert (8).

Beispielsweise wiesen $70 \%$ der Alkoholiker bei Entzugsbeginn mehr als $50 \mathrm{mg} / \mathrm{dl}$ HDL-Cholesterin auf (MW 67,0 $\pm 26,95 \mathrm{mg} / \mathrm{dl}$, mit Normalisierung nach 4-wöchiger $\mathrm{Ab}$ stinenz auf $37,37 \pm 13,09 \mathrm{mg} / \mathrm{dl}$ ). Positive Korrelationen zwischen steigendem Alkoholkonsum und HDL-Cholesterin wurden mehrfach beschrieben, aber auch solche zwischen GOT und $\gamma$-GT mit HDL-2/3. Mäßiger Alkoholkonsum soll zu erhöhtem HDL-3, chronischer Konsum jedoch zu erhöhtem HDL-2, führen $(10,11)$. Normalwerte werden ca. 1-4 Wochen nach Alkoholentzug erreicht (811). Als Ursache falsch positiver Erhöhungen wird ein Einfluß von Sedativa wie Phenobarbital, Tranquilizern und Lovastatin, aber auch von Training und körperlicher Belastung (Jogging) bzw. hoher Aktivität oder starkem Untergewicht diskutiert. Erniedrigte Spiegel wurden im übrigen bei Rauchen und hohem Körpergewicht festgestellt $(8,9)$.

Dem neuen Marker CDT (Carbohydrate Deficient Transferrin) wird von zahlreichen Autoren hohe Sensitivität $(50-90 \%)$ und vor allem hohe Spezifität $(90-100 \%)$ für regelmäßige Alkoholaufnahme bzw. Alkoholmißbrauch zugeschrieben $(1-3,7,17,18,28,30,31,33,35-40,42,46-$ $50,52,55-78,82,83)$.

Allerdings wurden in einigen Fällen auch geringere Sensitivitäten (ab 22\%) gefunden, jedoch bei regelmäßig hoher Spezifität über $90 \%(36,37,52)$. Erhöhte Werte werden vor allem bei Alkoholabusus ohne klinischen oder biochemischen Hinweis für Leberveränderungen gefunden, mit entsprechend höherer Sensitivität als $\dot{\gamma}$ GT $(7,30,46,82,83)$.

Die Transferrinsynthese erfolgt hauptsächlich in der Leber, wobei die Kohlenhydrateinheiten post-translational von einer Dolichol-Oligosaccharidvorstufe mittels eines Multiglykosyl-Transferasesystems gebunden werden (82). Bei CDT liegt ein reduzierter Gehalt an endständigen Kohlenhydratgruppen - Sialinsäure, Galaktose und Nacetyl-Glucosamin) vor. Als Ursache für die Defektbildung wird ein spezifischer und reversibler Effekt von Ethanol oder seinen Metaboliten auf die Lebersynthese von Transferrin angenommen, im Sinne einer Störung des Glycoprotein/Glycolipidstoffwechsels durch Glycosyltransferasen, oder von Membranstörungen durch chronische Alkoholbelastung $(34,47,64,65)$. Eine durch Acetaldehyd bewirkte Inhibition des Glycosyltransfers soll zumindest teilweise für die CDT-Bildung bei Alkoholmißbrauch verantwortlich sein (70).

Hohe Konzentrationen von Transferrin, aber auch CDT, finden sich im Serum, relativ niedrige dagegen in anderen Körperflüssigkeiten wie z.B. im Liquor cerebrospinalis. Die Bestimmung abnormer Transferrinvarianten mittels IEF wird auch zur Diagnose von Liquorfisteln verwendet $(41,55)$.

Neben dieser Mikroheterogenität ist auch ein genetischer Polymorphismus von Serumtransferrin durch isoelektrische Fokussierung (IEF) qualitativ erfaßbar und wichtiger Bestandteil u.a. in der Paternitätsbegutachtung $(19,24,32,66,79,80)$. Auch regelmäßiger hoher Alkohol- genuß führt jedoch zu Isotransferrinformen mit Mangel an Kohlenhydratresten, die weniger negativ geladen sind $(13,15,31,39,48-50,55-58,62,64)$. Mittels IEF und direkter Immunfixation wurde bei $81 \%$ von Patienten mit einem Alkoholkonsum von mehr als $60 \mathrm{~g} / \mathrm{Tag}$ eine abnorme kathodale Zusatzbande gefunden, die nach 10tägiger Abstinenz wieder verschwand $(58,59)$.

Nach einer Übersicht von Stibler (72) ist ein Konsum von mehr als 50-80g Ethanol/Tag für mindestens eine Woche erforderlich, um Erhöhungen in $81-94 \%$ der Fälle hervorzurufen. Über mögliche Einflüsse akuter, stärkerer Alkoholbelastung, beispielsweise in Form von Wochenendexzessen, waren keine genauen Angaben verfügbar.

Neben IEF und Densitometrie nach Immunfixation (24, $38,42,46-50,55-59)$ sowie Polyacrylamid-Gelelektrophorese und Immunoblotting $(39,40,42)$ wird zunehmend ein von Stibler et al. entwickeltes Mikrosäulenverfahren angewandt (62). Nach einer Erprobungsphase bei der Forschungsabteilung von Pharmacia Diagnostics $A B$, Uppsala wird dieses Verfahren bereits vielfach angewendet $(1-3,15,28,30,46,52,65-73,82,83)$. Die kommerzielle Einführung dieses quantitativen Radioimmunoassays eröffnet vielversprechende Perspektiven zur Alkoholismusdiagnose.

Vom Hersteller (Kabi Pharmacia Diagnostics) wird eine Sensitivität von ca. $90 \%$ und eine Spezifität von $99 \%$ für Patienten mit einem Alkoholkonsum von etwa $60 \mathrm{~g} / \mathrm{Tag}$ angegeben (82). Obere Normwerte für Personen ohne oder mit geringem Alkoholkonsum (bis 15 oder $40 \mathrm{~g}$ pro Tag) werden mit $20 \mathrm{U} / \mathrm{l}$, teils auch 22 oder $28 \mathrm{U} / \mathrm{l}$ für Männer und 26-27 U/I für Frauen angegeben $(3,52,82$, 83).

\section{Methanol, Aceton und Isopropanol}

Zum Stoffwechsel und Stellenwert von Methanol als Alkoholismusmarker gibt es inzwischen eine Reihe von Untersuchungen, deren Ausgangspunkt die Begleitstoffanalyse zur forensischen Beurteilung von Nachtrunkbehauptungen war $(6,14-16,20,26-28,45)$.

Humane, endogene Serummethanolkonzentrationen (SMK) liegen durchschnittlich bei $0,95 \mathrm{mg} / \mathrm{l}$ (Mittelwert $0,95 \mathrm{mg} / \mathrm{l}$, Bereich 0,35-3,2 mg/l, Normalverteilung mit positiver Schiefe, $n=508$ ) (16). Sie resultieren sehr wahrscheinlich aus dem endogenen und nicht aus dem enteralbakteriellen Stoffwechsel. Auch nutritive Quellen, wie methylesterreiches Obst, sind erst nach Aufnahme groBer Mengen relevant (16).

Nahezu alle alkoholischen Getränke enthalten Methanol, von geringen Mengen in Bier oder Wodka (wenige $\mathrm{mg} / \mathrm{l}$ ), mittleren Gehalten in Weiß/Rotwein $(30 / 100 \mathrm{mg} / \mathrm{l})$ bis zu höchsten Spiegeln in Obstbranntwein (ca. 1000-5000 $\mathrm{mg} / \mathrm{ll}(6,16)$. Trotzdem sind SMK über $10 \mathrm{mg} / \mathrm{l}$ durch kurzzeitige Alkoholaufnahme-ohne Aufnahme methanolreichen Obstbranntweins - nicht erreichbar und als Indikator für Alkoholmißbrauch anzusehen. Ein Konsum von Obstbranntwein ist durch andere, charakteristische $\mathrm{Be}$ gleitstoffe wie Propanol-1 und Butanol-2/Methylethylketon erfaßbar.

Ursache ist die ethanolbedingte Abbauhemmung endogenen und exogenen Methanols, die bei langzeitiger 
Alkoholaufnahme bzw. Alkoholisierung kumulativ zu erhöhten Spiegeln führt. Unterstrichen wird dies durch auffallende Koinzidenzen hoher Blutalkoholkonzentrationen mit SMK über $10 \mathrm{mg} / \mathrm{l}(6,14,20,26-29)$ sowie vor allem die häufige Beobachtung im stationären Alkoholentzug $(75 \%$ der Fälle mit SMK über $10 \mathrm{mg} / \mathrm{l})(14,16)$.

In der Alkoholisierungsphase oder bis zu ca. einem Tag nach vollständiger Ethanolelimination kann eine Methanolbestimmung aussagekräftig sein und als Kurzzeitmarker für Alkoholmißbrauch angesehen werden. Die Spezifität ist hoch einzuschätzen, wenn eine Aufnahme (erheblicher) Mengen von Obst oder von Obstbranntwein auszuschließen ist (16).

Über die Bedeutung erhöhter Isopropanol - wie teils auch Acetonspiegel als Folge von Alkoholabusus wurde ebenfalls berichtet $(14,27,28)$. Beide Stoffe sind in Nahrungsmitteln oder Alkoholika allenfalls in geringsten Mengen enthalten, relevante und ggf. verfälschende Isopropanolmengen jedoch in Desinfektionsmitteln (81).

Ein Isopropanolgrenzwert von $2 \mathrm{mg} / \mathrm{l}$ als Alkoholismusmarker (27) erscheint allerdings problematisch. Physiologische bzw. endogene Isopropanolgehalte im Blut oder Serum liegen an der Nachweisbarkeitsgrenze von ca. 0,1 $\mathrm{mg} / \mathrm{l}(14,27)$. Aufgrund der wechselseitigen Biotransformation (2.T. auch in vitro) von Aceton und Isopropanol über ADH ist vor allem bei Ethanolbelastung mit NADHÜberschuß eine Bildung von Isopropanol aus Aceton möglich $(14,16,27)$, besonders nach Nahrungsreduktion oder Fastenkuren mit vermehrter Acetonbildung $(16,27)$. Auffallend ist, daß sich im Gegensatz zu Alkoholikern im Entzug in einem Vergleichskollektiv alkoholauffälliger Kraftfahrer kaum erhöhte Werte und nicht einmal eine Koinzidenz hoher Aceton- oder Isopropanolspiegel mit hohen BAK-Werten fanden $(14,16)$.

Der Nachteil und die geringer einzuschätzende Bedeutung als Alkoholismusmarker gegenüber Methanol liegt daran, daß erhöhte Acetonspiegel in erster Linie metabolischen Ursprungs sind (Ketosen bei Hunger, Diabetes, starker körperlicher Belastung, Unterkühlung) und weniger direkter Alkoholeffekt. Bei fortgeschrittenem Alkoholismus häufiger auftretende Ernährungsstörungen können erhöhte Isopropanol und/oder Acetonspiegel mitverursachen $(14,16)$. Dies kann die Bedeutung als Alkoholismusparameter relativieren, andererseits jedoch zur Differentialdiagnose beitragen.

Alle genannten Alkoholismusmarker gewährleisten jedoch weder hinsichtlich der Spezifität noch vor allem der Sensitivität eine 100\%-ige Aussagesicherheit.

\section{Material und Methoden}

\section{Material}

Untersucht wurden 64 Serumproben von Personen 152 Männer, 12 Frauen, Alter 17-59 Jahre, im Mittel 33, 4 Jahre), denen Blutproben zur Frage eines Alkoholeinflußes bei unterschiedlichen Straftaten (Trunkenheit im Verkehr, Körperverletzung, Vergewaltigung u.a.) entnommen worden waren. Neben 52 alkoholpositiven wurden auch 12 alkoholfreie Proben aus demselben Kollektiv ausgewertet.

Außer Alter, Geschlecht, Beruf und Angaben zu einer Medikamenteneinnahme standen keine weiteren Charakteristika wie z.B. (verläßliche) Angaben zur Alkoholaufnahme zur Verfügung. Die Gesamtbeurteilung des blutentnehmenden Arztes zum Alkoholisierungsgrad wurde berücksichtigt $(\mathrm{nm}=$ nicht merkbar, $I=$ leicht, $\mathrm{ld}=$ leicht bis deutlich, $\mathrm{d}=$ deutlich, $\mathrm{s}=$ stark, ss = sehr stark unter Alkoholeinfluß). Insofern erhebt die Untersuchung nicht den Anspruch, diagnostische Wertigkeiten und Normalwerte zu sichern, sondern Screeningmöglichkeiten an einem nicht genau charakterisierten Kollektiv stichprobenartig aufzuzeigen.

Ferner wurden 10 Mitarbeiter der Medizinisch Immunologischen Laboratorien mit negativer Alkoholanamnese auf CDT untersucht.

\section{Methoden}

CDT wurde qualitativ und quantitativ im Serum bestimmt. Qualitativerfolgte der Nachweis mit der hochauflösenden isoelektrischen. Fokussierung (IEF) auf einem $0,5 \mathrm{~mm}$ dünnen Polyacrylamidgel $(250 \times 115 \mathrm{~mm})$ des $\mathrm{pH}$-Bereiches 4-8 (Gemisch aus 3\% Ampholine $\mathrm{pH} 4-6,5$ und 3\% Ampholine $\mathrm{pH}$ 5-8) und anschließendem Immunoprint mit einem monospezifischen Tf-Antiserum (DAKO). Die Serumproben $(50 \mu \mathrm{l})$ wurden mit $10 \mu \mathrm{l}$ 0,3\%-igem $\mathrm{FeCl}_{3}$ vorbehandelt und bei Raumtemperatur für etwa $1 \mathrm{Stun-}$ de inkubiert. Je $8 \mu$ l vorbehandeltes Serum wurden mit einem Applikationsstreifen in Kathodennähe auf das $\mathrm{Gel}$ aufgetragen. Als Elektrodenlösung diente für die Anode ein Gemisch aus $0,025 \mathrm{M}$ Asparaginsäure und $0,025 \mathrm{M}$ Glutaminsäure, für die Kathode 0,1M ß-Alanin. Bei einer Kühltemperaturvon $10^{\circ} \mathrm{C}$ und Maximalwerten von $1800 \mathrm{~V}$, $25 \mathrm{~mA}$ und $25 \mathrm{~W}$ dauerte die Fokussierung in einer Multiphorkammer etwa 200 Minuten. Für den Immunoprint wurde ein Celluloseacetatstreifen mit dem Antiserum (Verdünnung 3:1) getränkt und auf das Gel plaziert. Nach einer Reaktionsdauer von $2 \frac{1}{2}$ Minuten wurde der Fixierstreifen entfernt, 20 Minuten gewässert und schließlich mit Coomassie Brillantblau R-250 gefärbt und entfärbt. Die Tf-Bandenmusterwurden schließlich über einer Lichttafel identifiziert (vgl. Abb. 1). Die qualitative Bestimmung benötigte insgesamt etwa 4 Stunden.

Im normalen Serum der 10 Vergleichsfälle war CDT elektrophoretisch nicht nachweisbar.

Die quantitative CDT Bestimmung erfolgte in $0,5 \mathrm{ml} \mathrm{Se}-$ rum mittels eines Doppelantikörper-Radioimmunoassays (CDTect ${ }^{\mathrm{TM}}$, Kabi Pharmacia Diagnostics). Vorhandenes Transferrin wurde zunächst mit Eisencitrat gesättigt und in einer Mikrosäule in verschiedene Tf-Isoformen aufgetrennt. Das im Eluat vorhandene CDT konkurriert dann mit einer definierten, zugegebenen Menge an ${ }^{125} \mathrm{~J}$-markiertem Tf um die freien Bindungsstellen der spezifischen Antikörper. Gebundenes und freies Tf wurden anschließend durch Zugabe eines zweiten Antikörperimmunoadsorbens getrennt. Anschließend wurde zentrifugiert und dekantiert. Die im Pellet gemessene Radioaktivität ist dem in der Probe vorhandenen CDT umgekehrt proportional. Die Gesamtanalysendauer lag bei etwa 5 Stunden. 
Tabelle 1: Übersicht aller Parameter des untersuchten Kollektivs. Alter in Jahren; $B A K=B$ lutalkoholkonzentration in \%o; $C D T=C a r b o h y d r a t e$ Deficient Transferrin bzw. Kohlenhydratdefizientes Transferrin; Alkoholisierung $=$ Trunkenheitsgrad bei Blutentnahme mit $n m=$ nicht merkbar, I = leicht, Id = leicht bis deutlich, $d$ = deutlich, $d s$ = deutlich bis stark, s = stark, ss = sehr stark; Methanol-, Isopropanol-, Acetonserumspiegel, gamma-GT.

\begin{tabular}{l|l|l|l|l|l|l|l|l|} 
MANNER Alter(J) & CDT & BAK (\%o) & Alkoholisierung & Methanol & Isopropanol & Aceton & g-GT \\
\cline { 2 - 9 }
\end{tabular}

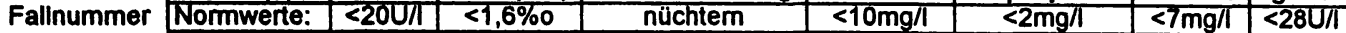

\begin{tabular}{|c|c|c|c|c|c|c|c|c|}
\hline 1 & 45 & 12,3 & 0,89 & 1 & 4,20 & 2,63 & 4,48 & 92 \\
\hline 2 & 46 & 12,9 & 0,98 & 1 & 4,67 & 0,60 & 2,82 & 20 \\
\hline 3 & 26 & 13,0 & 1,69 & $d$ & 3,50 & 0,73 & 2,06 & 13 \\
\hline 4 & 24 & 13,1 & 0,03 & $\mathrm{~nm}$ & 0,82 & 2,22 & 1,08 & 17 \\
\hline 5 & 35 & 13,3 & 0,02 & $\mathrm{~nm}$ & 0,37 & 0,35 & 10,28 & 16 \\
\hline 6 & 44 & 13,6 & 1,76 & Id & 6,23 & 3,68 & 0,20 & 64 \\
\hline 7 & 21 & 14,0 & 0,04 & $\mathrm{~nm}$ & 0,54 & 1,28 & 2,40 & 35 \\
\hline 8 & 33 & 14,2 & 0,02 & $\mathrm{~nm}$ & 0,70 & 0,22 & 1,70 & 29 \\
\hline 9 & 24 & 14,8 & 0,18 & $\mathrm{~nm}$ & 1,87 & 0,34 & 2,37 & 33 \\
\hline 10 & 33 & 15,6 & 0,02 & $\mathrm{~nm}$ & 0,59 & 0,28 & 6,20 & 25 \\
\hline 11 & 50 & 15,6 & 2,08 & $d$ & 9,22 & 5,53 & 0,22 & 21 \\
\hline 12 & 28 & 16,1 & 0,02 & $\mathrm{~nm}$ & 0,40 & 1,21 & 2,62 & 27 \\
\hline 13 & 28 & 16,2 & 1,65 & 1 & 7,00 & 2,38 & 1,75 & 28 \\
\hline 14 & 23 & 17,2 & 0,02 & $\mathrm{~nm}$ & 0.45 & 1,51 & 0,86 & 24 \\
\hline 15 & 35 & 17,4 & 2,51 & $d$ & 2,88 & 0,46 & 2,10 & 36 \\
\hline 16 & 47 & 18.1 & 2,05 & $d$ & 3,36 & 2,34 & 1,60 & 12 \\
\hline 17 & 42 & 18,1 & 1,72 & d & 5,90 & 3,26 & 2,20 & 140 \\
\hline 18 & 23 & 18,6 & 0,02 & Id & 0,55 & 2,51 & 1,60 & 36 \\
\hline 19 & 23 & 18,9 & 2,11 & d & 7,92 & 1,28 & 4,00 & 46 \\
\hline 20 & 50 & 20,0 & 1,50 & d & 6,12 & 0,41 & 3,12 & 15 \\
\hline 21 & 39 & 20,5 & 1,16 & $T$ & 10,30 & 5,10 & 4,52 & 108 \\
\hline 22 & 32 & 20,7 & 1,96 & d & 5,86 & 2,23 & 2,29 & 76 \\
\hline 23 & 40 & 21,0 & 0,78 & d & 3,27 & 0,38 & 1,53 & 31 \\
\hline 24 & 30 & 21,2 & 1,01 & $\mathrm{~nm}$ & 8,90 & 1,50 & 5,56 & 218 \\
\hline 25 & 32 & 21,5 & 2,00 & ds & 12,00 & 1,81 & 4,82 & 69 \\
\hline 26 & 27 & 23,8 & 0,03 & ss & 1,32 & 0,28 & 4,14 & 133 \\
\hline 27 & 39 & 23,9 & 0,72 & 1 & 3,02 & 0,38 & 2,60 & 71 \\
\hline 28 & 20 & 24,1 & 1.07 & Id & 6,60 & 0,48 & 2,48 & 25 \\
\hline 29 & 58 & 24,5 & 1.66 & $s$ & 5,60 & 7.42 & 1,55 & 141 \\
\hline 30 & 27 & 25.1 & 1,19 & 1 & 5,98 & 4.61 & 0,22 & 51 \\
\hline 31 & 55 & 25,5 & 0,62 & $1:$ & 9,92 & 1,16 & 6,20 & 39 \\
\hline 32 & 29 & 26,8 & 2,24 & $T$ & 7,95 & 3,07 & 3,74 & 31 \\
\hline 33 & 26 & 27,3 & 1,76 & $s$ & 4,01 & 3,11 & 0,20 & 28 \\
\hline 34 & 45 & 27,3 & 1,00 & 1 & 2,92 & 2.16 & 3.75 & 307 \\
\hline 35 & 17 & 28,1 & 0,68 & ss & 3,10 & 0,83 & 2,53 & 22 \\
\hline 36 & 22 & 29.1 & 1,26 & $d$ & 11,00 & 1,60 & 6,00 & 15 \\
\hline 37 & 22 & 29,5 & 0,01 & $\mathrm{~nm}$ & 1,01 & 0,63 & 1,67 & 79 \\
\hline 38 & 44 & 29,7 & 1,97 & 5 & 6,47 & 3,72 & 0,20 & 19 \\
\hline 39 & 27 & 37,9 & 1,22 & 1 & 2,75 & 0,52 & 1,17 & 21 \\
\hline 40 & -.59 & 38,0 & 2.15 & d & 10,65 & 1,17 & 3,00 & 56 \\
\hline 41 & 29 & 38,0 & 1,70 & 1 & 4,73 & 2,56 & 3,40 & 12 \\
\hline 42 & 28 & 43,5 & 1,54 & $\mathrm{~nm}$ & 7,10 & 1,74 & 2,10 & 181 \\
\hline 43 & 21 & 63,8 & 1,62 & 1 & 4,85 & 4,10 & 0,40 & 44 \\
\hline 44 & 34 & 54,1 & 1,91 & $d$ & 7,69 & 0,85 & 2,39 & 18 \\
\hline 45 & 46 & 89,1 & 2,80 & $d$ & 21,24 & 3,64 & 4,53 & 111 \\
\hline 46 & 22 & 60,0 & 1,58 & $\mathrm{~nm}$ & 12,07 & 2,10 & 5,50 & 188 \\
\hline 47 & 42 & 63,2 & 1,85 & Id & 5,18 & 1,43 & 2,11 & 40 \\
\hline 48 & 34 & 63,5 & 2,12 & d & 14,41 & 1,46 & 4,41 & 20 \\
\hline 49 & 31 & 74,2 & 2.69 & d & 19,77 & 3,12 & 10,34 & 94 \\
\hline 50 & 27 & 77,2 & 2,35 & $\mathrm{~nm}$ & 13,00 & 3,39 & 5,60 & 33 \\
\hline 51 & 41 & 93,1 & 2,34 & 1 & 40,10 & 8,80 & 13,20 & 67 \\
\hline $52^{\circ}$ & 41 & 171,9 & 2,38 & $\bar{d}$ & 28,63 & 3,07 & 7,47 & 70 \\
\hline FRAUEN & Normwerte: & $<26 \mathrm{U} / \mathrm{I}$ & $<1,6 \%$ & nüchtern & $<10 \mathrm{mg} / \mathrm{l}$ & $<2 m g / 1$ & $<7 \mathrm{mg} / \mathrm{l}$ & $<18 \mathrm{U} / \mathrm{I}$ \\
\hline 53 & 27 & 13,6 & 0,04 & $\mathrm{~nm}$ & 0,90 & 0.50 & 2,60 & 13 \\
\hline 54 & 29 & 15,9 & 0,45 & 1 & 2,80 & 0,36 & 2,50 & 28 \\
\hline 55 & 39 & 16,1 & 1,66 & Id & 2,97 & 1,75 & 2,23 & 32 \\
\hline 56 & 52 & 17.5 & 2,03 & 1 & 26,71 & 6.67 & 1,80 & 332 \\
\hline 57 & 33 & 19,7 & 1,69 & d & 5,60 & 0,64 & 3,10 & 14 \\
\hline 58 & 27 & 21,4 & 0.03 & $\mathrm{~nm}$ & 0.62 & 0,89 & 2,97 & 28 \\
\hline 59 & 47 & 22,3 & 1,77 & d & 13,44 & 6,34 & 0,40 & 67 \\
\hline 60 & 47 & 28,4 & 2,63 & $\mathrm{~nm}^{\circ}$ & 8,33 & 3,67 & 2,00 & 24 \\
\hline 61 & 38 & 31.7 & 1,88 & Id & 7,66 & 2,24 & 3,00 & 13 \\
\hline$\sigma 2$ & 38 & 33,4 & 1,00 & 1 & 3,80 & 0,39 & 1,65 & 13 \\
\hline 63 & 30 & 68,0 & 1,80 & 1 & 8.27 & 1.78 & 2,63 & 30 \\
\hline 64 & 44 & 63,2 & 2,92 & d & 21,67 & 2,19 & 4.98 & 171 \\
\hline
\end{tabular}


Nach Herstellerinformationen ist dieser CDT-Assay für Serum gut geeignet, jedoch nicht für Plasma und vor allem nicht für Citratplasma. Die Stabilität wird beiProbenlagerung bei $2-8^{\circ} \mathrm{C}$ mit bis zu 48 Stunden angegeben, bei $-20^{\circ} \mathrm{C}$ bis zu einem Jahr. Das Eluat kann bei $2-8^{\circ} \mathrm{C}$ für eine Woche aufbewahrt werden. Hämolyse soll angeblich ohne Auswirkungen sein. Dies ist jedoch noch nicht ausreichend untersucht, möglicherweise kann es zu Verdünnungseffekten kommen. Wiederholtes Einfrieren und Auftauen ist zu vermeiden (77).

Die Testcharakteristika weisen eine Wiederfindungsrate (recovery) von $102 \%$ und Variationskoeffizienten zwischen 4,6 und $9,6 \%$ aus.

Über Untersuchungen von Leichenproben liegen bisher keine Erfahrungen vor. Bei bakterieller Kontamination bestehe ein relevantes Risiko für einen enzymatischen Abbau von Transferrin und eine Zunahme von CDT.

Methanol, Aceton und Isopropanol (einschließlich anderer flüchtiger Substanzen) wurden im Wege der Begleitstoffanalyse mittels spezialisierter Head-Space Gaschromatographie mit Kapillarsäule bestimmt. $0,25 \mathrm{ml}$ Serum oder Blut wurden mit $0,5 \mathrm{ml}$ Perchlorsäure/ Perchlorat enteiweißt, sodann wurden $0,5 \mathrm{~g}$ wasserfreies $\mathrm{Na}_{2} \mathrm{SO}_{4}$ zur Dampfdruckerhöhung und $0,1 \mathrm{ml}$ TertiärButanol als interner Standard zugegeben. Verwendet wurde eine Kapillarsäule mitFlammenionisationsdetektor und Temperaturprogramm, Kalibration/Eichung erfolgten gegen wässrigen Standard.

Der Probenlauf erstreckt sich über 15 Minuten, insgesamt wird etwa 1 Stunde zur Analyse benötigt. Diese Methode wird routinemäßig angewandt $(16,81)$.

Die Blutalkoholkonzentration (BAK, in \%o) war vorher in behördlichem Auftrag nach den Richtlinien zur forensischen BAK-Bestimmung bestimmt worden (Mittelwert aus je 2 automatisierten Einzelbestimmungen nach der GC- und der ADH-Methode). Im Rahmen der ADH-Methode zur Alkoholbestimmung am Analysenautomaten (Technicon $\left.{ }^{\otimes}\right)$ wird dabei seit einiger Zeit simultan die $\gamma$ GT mitbestimmt (bei $25^{\circ} \mathrm{C}$ Reaktionstemperatur, Normwerte: Männer 6-28 U/I, Frauen 4-18 U/I).

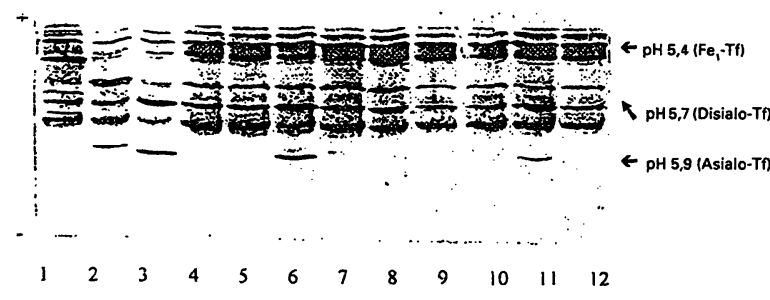

Abb. 1: Transferrin-Bandenmuster nach der isoelektrischen Fokussierung von Seren auf einem Polyacrylamidgel des $\mathrm{pH}$-Bereiches 48 und anschließender Printimmunfixation mit einem monospezifischen Tf-Antiserum. Die Proben Nr. 4-11 stammen aus dem untersuchten Personenkreis, wobei gleichzeitig folgende quantitativen Werte gemessen wurden: (Spur 4) 19 U/l; (5) 27 U/l; (6) 172 U/l; (7) $22 \mathrm{U} / \mathrm{l} ;$ (8) $21 \mathrm{U/I}$; (9) $20 \mathrm{U/l}$; (10) $32 \mathrm{U} / \mathrm{l}$ und (11) $74 \mathrm{U} / \mathrm{ll}$. Zum direkten Vergleich der einzelnen Banden ist in Spur (1) der Phänotyp Tf C1Dchi, in (2) Tf C1D2 und in (12) Tf C1 dargestellt. Bei Spur (3) handelt es sich um die Probe eines Patienten mit CDG-Syndrom (siehe Text). Die Anode ist oben.

\section{Ergebnisse}

Tab. 1 zeigt eine Übersicht der Ergebnisse der 64 untersuchten Personen getrennt nach Geschlechtern und geordnet nach zunehmenden CDT-Werten. Normüberschreitende Werte erscheinen fett gedruckt. Der BAKGrenzwert von 1,6\% wurde in Anlehnung an Richtlinien desTÜV (Technischer Überwachungsverein) zurWieder-

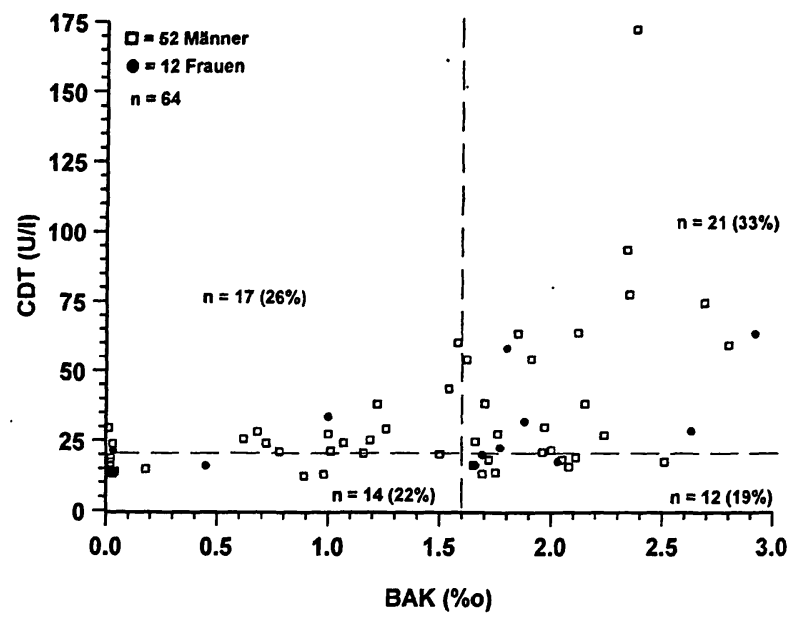

Abb. 2: Punktdiagramm von $C D T$ und BAK. Gestrichelte Linien kennzeichnen obere Normgrenzen. In 33\% liegen sowohl erhöhte CDT - ( $>20$ bei Männern und $>26$ U/I bei Frauen) als auch BAK-Werte vor, in $26 \%$ BAK-Werte $<1,6 \%$ bei erhöhtem CDT. Insgesamt sind die CDT-Werte in $59 \%$ der Fälle erhöht. Korrelative Beziehungen bestehen bei $r=0,48$ nicht.

erteilung der Fahrerlaubnis nach Trunkenheitsdelikten und unter der Annahme gewählt, daß Werte über 1,6\%。 durch normales, auch einmalig exzessiveres Trinkverhalten ohne gleichzeitige, massive Trunkenheitssymptome nicht erreichbar sind und bereits auf Alkoholtoleranz und Alkoholmißbrauch hinweisen.

\section{$C D T$}

Abb. 1 zeigt Transferrin-Bandenmuster nach isoelektrischer Fokussierung von Seren auf einem Polyacrylamidgel mit anschließendem Immunoprint. Ein Vergleich der qualitativen und quáṅtitativen CDT-Ergebnisse ergab, daß ab $20 \mathrm{U} / /$ bereits schwache Banden nachweisbar sind. Die Bandenintensität von Asialo- und Disialotransferrin nimmt mitsteigender CDT-Konzentration deutlich zu. Als Kontrolle dienten die Seren von 10 Mitarbeitern der Medizinisch Immunologischen Laboratorien, die sämtlich unauffällige, nicht erhöhte CDT-Werte (MW: 14 U/I) und keine IEF-Zusatzbanden aufwiesen.

$63 \%$ der Männer und $42 \%$ der Frauen (insgesamt $59 \%$ ) hatten CDT-Werte über der Norm.

Korrelative Beziehungen zu BAK $(r=0,48), \gamma-G T(r=0,09)$, Isopropanol $(r=0,21)$ oder Trunkenheitsgrad waren nicht erkennbar (vgl. Abb. 2-4), ebenso nicht zu Aceton ( $r=$ $0,47)$, jedoch in geringerem Ausmaß zur SMK $(r=0,69)$. Zusammenhänge mit dem Lebensalter waren nicht $a b$ - 
grenzbar, auch nicht in den Fällen mit erhöhten CDTWerten $(r=0,09)$.

Auffallend ist, daß auch 2 alkoholnegative Personen (Fall 26 und 37) und 6 Personen mit $<1 \%$ BAK erhöhte CDTWerte hatten. Andererseits gab es auch Fälle mit erhöhten BAK, SMK und/oder $\gamma$-GT-Spiegeln bei unauffälligem CDT (z.B. Fall 56!).

\section{Methanol}

Insgesamt hatten $23 \%$ aller Fälle SMK über $10 \mathrm{mg} / \mathrm{l}$, bei BAK-Werten über $2 \%$ waren es $63 \%$ (vgl. Abb. 5). Mit den anderen Parametern ergeben sich folgende Korrelationskoeffizienten: CDT $(r=0,69)$, Isopropanol $(r=0,54)$, Aceton $(r=0,56)$, BAK $(r=0,64), \gamma$-GT $(r=0,34)$.

\section{$\gamma-G T$}

$63 \%$ aller Fälle hatten Spiegel über der jeweiligen Normgrenze, davon einige mit normalen Werten von CDT, BAK oder SMK. (CDT: $r=0,09$; BAK: $r=0,14$; SMK: $r=0,34$; Isopropanol: $r=0,35$; Aceton: $r=0,13$ ).

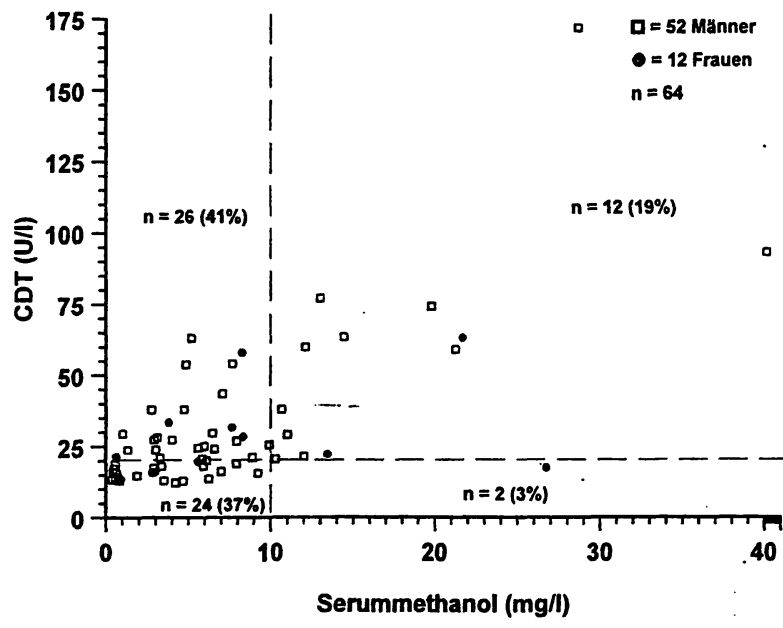

Abb. 3: Punktdiagramm von CDT und $S M K(r \doteq 0,69)$. Gestrichelte Linien kennzeichnen obere Normgrenzen. In 19\% der Fälle besteht gleichzeitige Erhöhung, in $41 \%$ erhöhte CDT-Werte bei "normalen" $S M K<10 \mathrm{mg} /$.

\section{Isopropanol}

$47 \%$ aller Fälle hatten Werte über $2,0 \mathrm{mg} / \mathrm{l}$. Auch die Isopropanolspiegel waren gegenüber BAK, SMK, CDT und $\gamma$-GT uncharakteristisch verteilt (BAK: $r=0,48$; SMK: $r=0,54$; CDT: $r=0,21 ; \gamma-G T: r=0,35$; Aceton: $r=-0,011$.

Beispielsweise hatten $30 \%$ sowohl erhöhte Isopropanolals auch CDT-Werte, jedoch auch $25 \%$ gleichermaßen Werte im Normbereich.
Zusammenhänge mit dem Lebensalter waren für keinen Parameter nachweisbar.

Wie zu erwarten, bestanden auch keine wertbaren $\mathrm{Zu}$ sammenhänge zwischen Trunkenheitsgrad und BAK oder anderen Parametern.

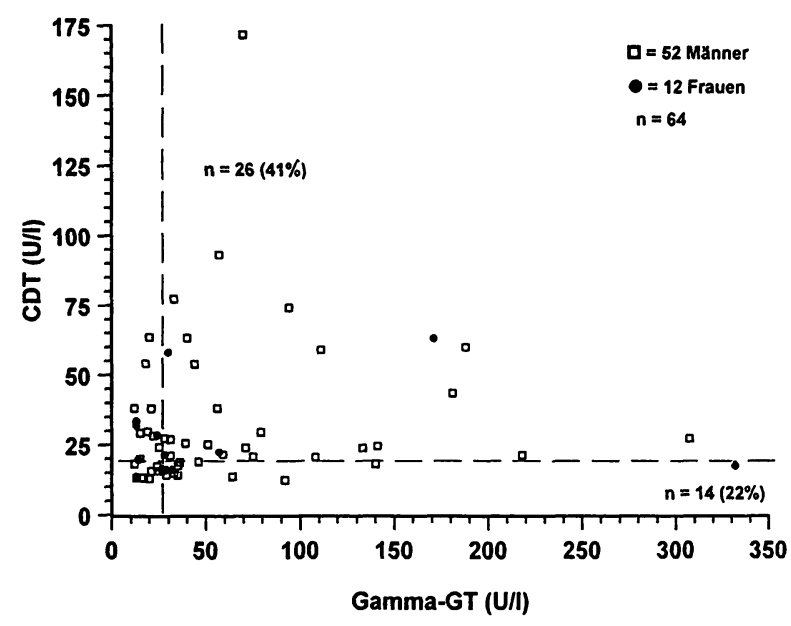

Abb. 4: Punktdiagramm von CDT und $\gamma-G T(r=0,09)$. Gestrichelte Linien kennzeichnen obere Normgrenzen. In $41 \%$ gleichzeitige Erhöhungen, in $22 \%$ erhöhte $\gamma$-GT beinormalem CDT, in $20 \%$ normale $\gamma$-GT bei erhöhtem CDT.

\section{Diskussion}

Im Untersuchungskollektiv standen weitere anamnestische und klinische Daten nicht zur Verfügung. Insofern waren weder eine Diagnose von Alkoholmißbrauch oder Alkoholabhängigkeit möglich noch Schlußfolgerungen hinsichtlich der Spezifität oder Sensitivität einzelner Parameter oder von Zusammenhängen mit dem täglichen Alkoholkonsum. Dies entspricht jedoch vielfach der Situation in der Begutachtungspraxis und dem Charakter von Alkoholismusindikatoren.

Zumindest ist in den Fällen mit erhöhter SMK nachweisbar, daß es sich nicht um eine kurzzeitige Alkoholaufnahme und Alkoholisierung im Bereich einiger Stunden gehandelt hat. Dies kommt auch darin zum Ausdruck, daß der Prozentsatz erhöhtér SMK bei gleichzeitiger BAK über $2 \%$ mit $63 \%$ deutlich anstieg und vergleichbar mit früheren Ergebnissen ist (14-16, 20, 26, 27, 29, 45).

Der auffallend hohe Anteil an Normwertüberschreitungen bei CDT in durchschnittlich $60 \%$ aller Fälle kann darauf zurückgeführt werden, daß CDT bereits auf relativ niedrige, jedoch tägliche Alkoholbelastungen, beispielsweise von 50-80 güber zumindest eine Woche, mit einer Erhöhung reagiert (72). Leicht erhöhte CDT-Werte können somit auch bei sog. Konsumtrinkern auftreten. Insofern erscheint es problematisch, eine tägliche Alkoholaufnahme von $50 \mathrm{~g}$ ohne Berücksichtigung von $\mathrm{Ge}-$ schlecht und Körpergewicht mit Alkoholmißbrauch oder gar Alkoholismus gleichzusetzen und als alleinige Beurteilungsgrundlage heranzuziehen. Die Angabe von Alkoholbelastungen in $\mathrm{g} / \mathrm{kg}$ würde sicherlich präzisere Aussa- 
gen ermöglichen. Beim momentanen Kenntnisstand und insbesondere unter forensischen Kriterien scheint ein Grenzwert von $30 \mathrm{U} / \mathrm{l}$ zum sicheren Nachweis eines Alkoholmißbrauchs realistischer. Dieser cut-off Wert wurde bereits von Iffland für forensische Zwecke vorgeschlagen (28) und entspricht beispielsweise auch eher dem von Kanitz et al (30) angegeben, oberen Grenzbereich (33 U/I als oberer 3s-Wert bei gesunden Männern und Frauen mit einem Alkoholkonsum von weniger als $20 \mathrm{~g} / \mathrm{Tag}$ bzw. $29,2 \mathrm{U} / /$ bei $20-40 \mathrm{~g} / \mathrm{Tag}$ ).

Falsch positive CDT-Erhöhungen sind im übrigen bisher nur in seltenen Fällen ausgeprägter und chronischer Leberinsuffizienz bekannt $(1,30,65,68)$ sowie vereinzelt bei Schwangerschaft und extremem Eisenmangel bei Frauen (30). In sehr seltenen Fällen wäre auch an geneti-

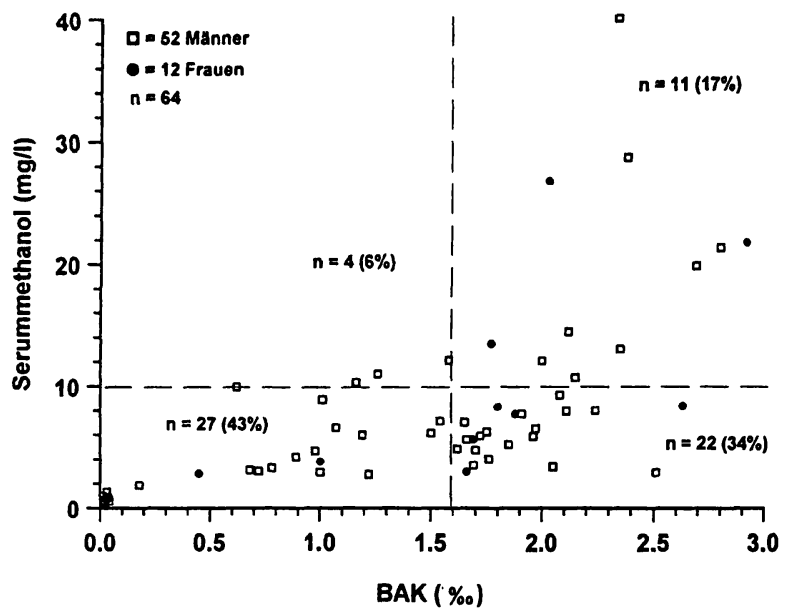

Abb. 5: Punktdiagramm von SMK und BAK $(r=0,64)$. Gestrichelte Linien kennzeichnen obere Normgrenzen. In $51 \%$ aller Fälle BAK $>1,6 \%$, lediglich in $17 \%$ BAK und SMK erhöht.

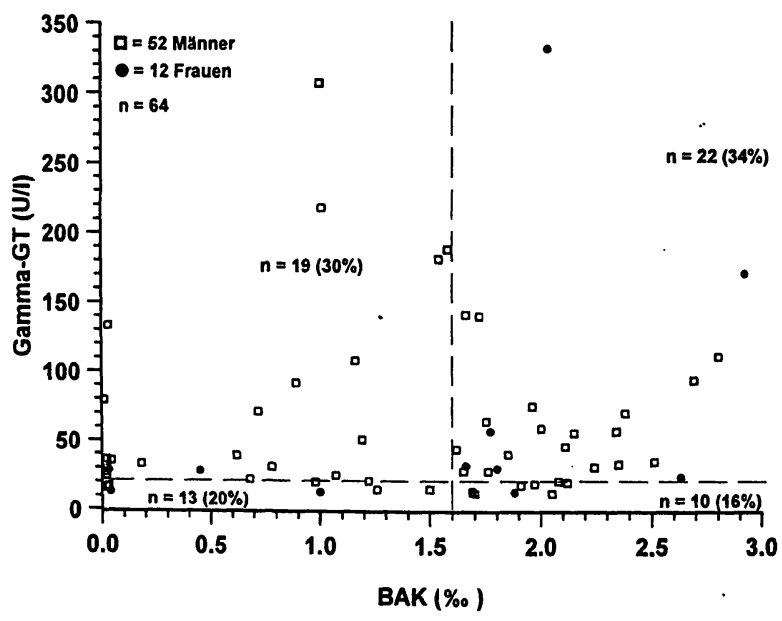

Abb. 6: Punktdiagramm vori BAK und $\gamma-G T(r=0,14)$. Gestrichelte Linien kennzeichnen obere Normgrenzen. 34\% der Fälle mit gleichzeitiger Erhöhung, in immerhin 30\% ergeber sich BAK-Werte $<1,6 \%$ bei teils sehr deutlicher $\gamma$-GT Erhöhung. sche Varianten mit erhöhten Werten zu denken wie z.B. Glykanose CDG $(25, \mathrm{vgl} .13,19,32,39,79,80)$. Dies unterstreicht die hohe Spezifität des CDT, zumindest zum Nachweis täglicher Alkoholkonsummengen ab 50-80 g. Anzumerken ist, daß die Diagnose von Liquorfisteln durch die Bestimmung abnormer Transferrinvarianten mittels IEF $(41,55)$ bei entsprechendem Alkoholmißbrauch zumindest problematisch werden kann.

Der Anteil erhöhter Isopropanolspiegel war größer als bei früheren Untersuchungen. (14,15), was möglicherweise auf andere Ernährungssituationen oder in-vitro Veränderungen (Bildung von Isopropanol aus Aceton) zurückgeführt werden kann.

Fehlende Zusammenhänge zwischen alkoholbedingten, äußeren Ausfallerscheinungen und der BAK entsprechen der täglichen Begutachtungserfahrung und sind auf Alkoholtoleranz zurückzuführen. Insofern ist der Verdachtsgrenzwert von 1,6\%o als Anlaß zur Überprüfung der allgemeinen Fahrtauglichkeit zunächst durch-

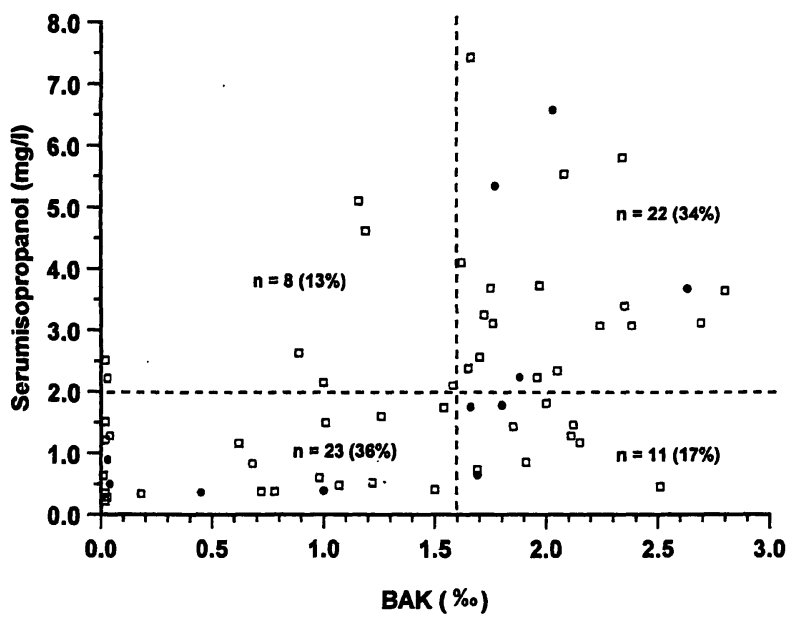

Abb. 7: Punktdiagramm von Isopropanol und BAK $(r=0,48)$. Gestrichelte Linien kennzeichnen obere Normgrenzen. In 34\% sowohl Isopropanol wie auch BAK erhöht, in $25 \%$ beide im Normbereich.

aus nachvollziehbar. Personen mit "normalen" Trinkgewohnheiten erreichen BAK-Werte über $1,6 \%$ üblicherweise nicht oder zeigen dann erwartungsgemäß deutliche Trunkenheitssymptome.

Die bei jüngeren Personen häufig noch nicht so ausgeprägte Intensität und Chronizität eines Alkoholabusus führt möglicherweise noch nịcht zu Veränderungen der $\gamma$-GT, während CDT mit einer kürzeren $\mathrm{HWZ}$ von ca. 14 Tagen bereits reagieren kann. Altersabhängigkeiten von CDT-Erhöhungen, BAK und $\gamma$-GT, wie von Iffland beschrieben (28), waren jedoch nicht erkennbar, was möglicherweîse auf die geringe Fallzahl zurückzuführen ist. Genauere statistische Untersuchungen, eine Einteilung in Altersgruppen und Überprüfung mittels Rangkorrelationskoeffizienten nach Spearman setzen größere Fallzahlen voraus; eine entsprechende Erweiterung der Untersuchungen ist geplant. 
Zusammenhänge zwischen CDT und SMK $(r=0,69)$ könnten auf ähnliche, ethanolbedingte und inhibierende Stoffwechselreaktionen zurückzuführen sein. Der Inhibition des Methanolabbaus durch Ethanol entspricht möglicherweise die alkoholbedingte Abbauhemmung von Dolichol, die zu Störungen der Glycosylierung und somit zur Erhöhung von CDT führen könnte. Dolichole sind primäre, langkettige Alkohole, die eine Rolle bei der Biosynthese von Glykoproteinen bzw. bei Glycosylierungsreaktionen spieien. Bei chronischen Alkoholikern, teils auch nach körperlicher Belastung, wurden erhöhte Werte im Urin gefunden. Auch erhebliche Alkoholbelastung über 1-2 Tage, nicht jedoch moderate Aufnahme über 10 Tage, kann zu erhöhten Spiegeln führen (44). Die Normalisierung erfolgt mit einer HWZ von ca. 3 Tagen $(44,45)$. Ob diese ethanolbedingte Abbauhemmung von Dolichol über die biologische Halbwerts/Synthesezeit des Transferrins zu entsprechender (Fehl-) Bildung von CDT führen kann - womit letzlich die protrahierte Alkoholisierung mit Abbauhemmung über biochemische Mechanismen zur CDT-Erhöhung führen würde - müßte noch geklärt werden.

Allerdings werden erhöhte Methanolspiegel nach Wegfall der ethanolbedingten Abbauhemmung relativ rasch eliminiert (HWZ = ca. 2,4 $\pm 0,5$ h) (16), während die Synthesestörung von CDT bei einer HWZ von 14-17 Tagen

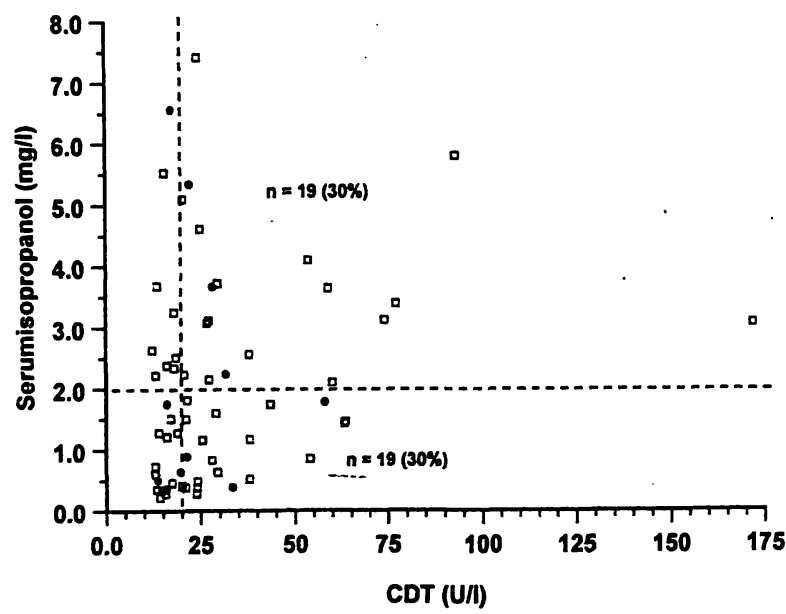

Abb. 8: Punktdiagramm von Isopropanol und $C D T(r=0,21)$. Gestrichelte Linien kennzeichnen obere Normgrenzen. In $30 \%$ der Fälle sind sowohl lsopropanol wie auch CDT erhöht, in weiteren $30 \%$ lediglich CDT.

(30) eine längerzeitige Alkoholexposition erfordert. Dies kann die mäßige Korrelation der beiden Parameter erklären.

Wie mehrfach und auch für MCV beobachtet $(3,8,18,30$, $72,82,83$ ) korrelierten auch in unsrerer Untersuchung sämtliche Parameter untereinander nicht, so daß sich durch Kombination die diagnostische Effizienz verbessern und differenzieren läßt.

Prinzipiell und analog zum Diabetes mellitus könnte man auf den unterschiedlichen, zeitintegrierenden Charakter der einzelnen Parameter abstellen. Dem aktuellen, punktuellen Blutzuckerwert beim Diabetes mellitus entspräche die BAK und Harnzuckerwerten etwa die Methanolspiegel, während CDT, $\gamma$-GT und MCV ähnlich wie glykosiliertes Albumin/Fructosamin und glycosyliertes Hämoglobin zeitintegrierend die chronische Stoffwechselbelastung mit Alkohol widerspiegeln.

Insofern repräsentiert die BAK die aktuelle Alkoholisierung, Methanol eine Alkoholbelastung über wenigstens zahlreiche Stunden und CDT eine solche von zumindest 1-2 Wochen, $\gamma$-GT über mindestens 2-4 Wochen und MCV etwa 2-3 Monate, entsprechend der durchschnittlichen Lebensdauer der Erythrozyten.

HDL-Cholesterin und Apolipoprotein wären unter diesem Aspekt neben CDT als Alkoholismusmarker wertvoll. Wir führen deshalb derzeit eine vergleichende Studie von MCV, $\gamma$-GT, HDL-Cholesterin, Apolipoprotein, CDT u.a. an Alkoholikern im Entzug durch.

Für die Praxis ist von Bedeutung, daß qualitative und quantitative CDT- wie auch $\gamma$-GT-Bestimmungen nur an frisch gewonnenen oder tiefgefrorenen Serumproben möglich sind. Weniger kritisch als der CDT-Assay scheint die IEF zu sein, die nach eigenen Erfahrungen bei kleinerer Probenmenge und etwas geringerer Analysendauer eine geringere Anfälligkeit für Lagerungsveränderungen aufweist und eine Bestimmung auch nach mehrmaligem Einfrieren und Auftauen erlaubt. Allerdings bleibt die Methode Speziallabors vorbehalten. In aller Regel werden Serumüberstände nach forensischer Alkoholbestimmung nicht abpipettiert und eingefroren. Insofern sind entsprechende Analysen meist erst durch nachträgliche Blutentnahmen möglich, beispielsweise anläßlich einer Überprüfung der allgemeinen Fahreignung vor Wiedererteilung einer Fahrerlaubnis nach Trunkenheitsfahrt.

Der Vorteil der Methanol- und Begleitstoffbestimmung liegt in der Möglickeit, Untersuchungen auch noch nach mehrmonatiger Lagerung durchzuführen. Zur Beurteilung der allgemeinen Verkehrstauglichkeit im Rahmen medizinisch-psychologischer Tests ist nach unserer Auffassung die Möglichkeit einer Beurteilung der Trinkgewohnheiten zum Vorfallszeitpunkt durchaus aussagekräftig, vor allem im Vergleich mit der Situation zum Untersuchungszeitpunkt.

Unsere Untersuchungen weisen darauf hin, daß auch Alkoholmißbrauch oder Alkoholabhängigkeit l,fahrenden Trinker") bei Personen mit niedrigen BAK-Werten entdeckt werden können, was die Sicherheit im Straßenverkehr erhöhen kann, während "normale" bzw. Konsumtrinker ("trinkende Fahrer") von teuren und zeitraubenden medizinisch-psychologischen Tests durch tatzeitbezogene oder auch spätere Bestimmung mehrer Alkoholparameter verschont bleiben könnten. 


\section{Originalie}

\section{Literatur:}

1. Behrens, U., Worner, T.M., Braly, L.F. ot al (1988): Carbohydrate-deficient transferrin, a marker for chronic alcohol consumption in different ethnic populations, Alcohol Clin Exp Res 12, 427-432.

2. Behrens, U.J., Worner, T.M., Lieber, C.S. (1988): Changes in carbohydratedeficient transferrin levels after alcohol withdrawal, Alcohol Clin Exp Res 12 539-542.

3. Bell, H., Tallaksen, C., Sjaheim, T. et al (1993): Serum carbohydrate-deficient transferrin as a marker of alcohol consumption in patients with chronic liver diseases, Alcohol Clin Exp Res 17, 246-252.

4. Chick, J., Kreitmann, N., Plant, M. (1981): Mean cell volume and gamma glutamyl-transpeptidase as markers of drinking, in working men, Lancet 1 , $1249-1251$.

5. Beresford, T.P., Blow, F.C., Hill, E., Singer, K., Lucey, M.R. (1990): Comparison of CAGE questionnaire and computer-assisted laboratory profiles in screening for covert alcoholism, Lancet 336, 482-485.

6. Bonte, W. (1987): Begleitstoffe alkoholischer Getränke, Schmidt-Römhild Verlag.

7. Chan, A.W., Leong, F.W., Schanley, D.L. et al (1989): Transferrin and mitochondrial aspartate aminotransferase in young adult alcoholics, Drug Alc Dep 23, 13-18.

8. Clemens, M.R., Schied, H.W., Daiss, W., Waller, H.D. (1986): Lipid abnormalities in plasma and red cell membranes of chronic alcoholics, Klin Wschr 64, 181-185.

9. Crow K.E., Batt, R.D. (Hrsg) (1989): Human metabolism of alcohol (Vol III), CRC Press, Boca Raton, Florida.

10. Cushman, P., Barboriak, J., Kalbfleisch, J. (1986): Alcohol: high density lipoproteins, apolipoproteins, Alcohol Clin Exp Res 10, 154-157.

11. Dai, W.S., Laporte, R.E., Hom, D.L. et al (1985): Alcohol consumption and high density lipoprotein cholesterol concentration among alcoholics, Am J Epidemiol 122, 620-628.

12. Feuerlein, W. (1991): Alkoholismus: Definition,Diagnose, Krankheitsbegriff, Ablauf, Ergebnisse und Kosten der Behandlung, Versicherungsmedizin 43, 21-27.

13. Geserick, G., Nickel, B., Schröder, H., Zieschank, R., Otto, B. (1990): Beitrag zur Personenidentifizierung durch nicht genetische Blutmerkmale, Medicina Forensis Lipsiensis 1990, 79-84.

14. Gilg, T., Soyka, M., v.Meyer, L., Ora, I. (1989): Methanol und Isopropano als biochemische Alkoholismusmarker-Psychiatrische und forensische Aspekte, Nervenheilkunde 8, 105-113.

15. Gilg, T., Josephi, E., Tutsch-Bauer, E., v.Meyer, L. (1991): Methanol, gamma-GT, carbohydrate-deficient transferrin und alpha-1 antitrypsin in Nativund Leichenblutproben: Zusammenhänge und Stellenwert als Alkoholismusmarker? Zbl Rechtsmed 36, 169.

16. Gilg, T.: (1993): Methanol: Stoffwechsel bei kurzzeitiger und chronische Alkoholaufnahme und Stellenwert als biochemischer Alkoholismusmarker, Habilitationsschrift Ludwig-Maximilians-Universität München.

17. Gjerde, H., Mörland, J. (1987): Concentrations of carbohydrate-deficient ransferrin in dialysed plasma from drunken drivers, Alcohol and Alcoholism 22, 271-276.

18. Gjerde, H., Johnsen, J., Bjorneboe, A. et al (1988): A comparison of serum carbohydrate-deficient transferrin with other biological markers of excessive drinking, Scand J Clin Lab Invest 48, 1-6.

19. Görg, A., Weser, J., Westermeier, R. et al (1983): Isoelectric focusing with immobilized $\mathrm{pH}$ gradients for the analysis of transferrin (Tf) subtypes and variants, Hum Genet 64, 222-226.

20. Grüner, O., Bilzer, N. (1985): Zur Teilnahme chronischer Alkoholiker am Straßenverkehr, Blutalkohol 22, 209-223.

21. Haffner, H.T., Krämer, M., Zink, P. (1988): Veränderungen der Leberenzymwerte im Verlauf einer 36 stündigen Alkoholbelastung, Blutalkohol 25, 116 126.

22. Haffner, T., Becker, I.S., Mann, K. (1989): Zur Sensitivität klinisch-chemischer Marker des Alkoholismus nach kurzfristiger anlaßbezogener Alkoholkarenz, Blutalkohol 26, 116-124.

23. Haffner, H.T. ( 1993): Alkoholauffällige Verkehrsteilnehmer - Epidemiologische Studie mit kritischen Schlußfolgerungen für die Eignungsrichtlinien, Ver!ag TüV Rhein!and GmbH Kö!n.

24. Heegaard, N.H., Hagerup, M., hompsen, A.C., Heegard, P.M. (1989): Concanavallin A crossed affinity immunelectrophoresis and image analysis for semiquantitative evaluation of microheterogeneity profiles of human serum transferrin from alcoholics and normal individuals, Electrophoresis 10, 836840.

25. Heyne, K., Weidinger, S. (1992): Diagnostik und Nosologie der Glykanose CDG ("Carbohydrate-deficient glycoproteinsyndrome"), Monatsschr Kinderheilkd 140, 822-827.

26. Iffland, R., Kaschade, W., Heesen, D., Mehne, P. (1984): Untersuchungen zur Bewertung hoher Methanolspiegel bei Begleitalkohol-Analysen, Beitr Ge Med 42, 231-236.

27. Iffland, R., Staak, M. (1990): Methanol und Isopropanol als Alkoholismusmarker, Beitr Ger Med 48, 173-177.

28. Iffland, R. (1993): CDT, $\gamma$-GT und Methanol als Alkoholismusindikatoren in Blutproben alkoholauffälliger Kraftfahrer, Fortschr Diagn 4 (Praxis Report 5) 17-22.
29. Jones, A.W., Löwinger, H. (1988): Relationship between the concentration of ethanol and methanol in blood samples from Swedish drinking drivers, For Sci Int 37, 277-285.

30. Kanitz, R.D., Wetterling, T., Missler, U. (1993): Carbohydrate deficient Transferrin als Indikator zur Objektivierung eines pathologisch erhöhten Alkoholkonsums, Fortschr Diagn 4 (Praxis Report 5).

31. Kapur, A., Wild, G., Milford-Ward, A., Triger, D.R. (1989): Carbohydrate deficient transferrin: a marker for alcohol abuse, Br Med J 299, 427-431.

32. Kühnl, P., Spielmann, W. (1979): A third common allele in the transferrin system, Tf-C3, detected by isoelectric focusing. Hum Genet 50, 193-198. 33. Kwoh-Gain, I., Fletcher, L.M., Price, J. et al (1990): Desialylated transferrin and mitochondrial aspartate aminotransferase compared as laboratory markers of excessive alcohol consumption, Clin Chem 36, 841-845.

34. Malagolini, N., Dall'Olio, F. et al (1985): Effect of acute and chronic ethanol administration on rat liver alpha 2,6-sialyltransferase activity responsible for sialylation of serum transferrin, Alcohol Clin Exp Res 13, 649-653.

35. Moirand, R., Lescoat, G., Brissot, P. (1989): Interaction of alcohol and iron proteins, Ann Gastroenterol Hepatol 25, 51-54.

36. Nilssen, O., Huseby, N.E., Hoyer, G. et al (1992): New alcohol markers How useful are they in population studies: The Svalbard study 1988-1989, Alcohol Clin Exp Res 16, 82-86.

37. Nyström, M., Peräsalo, J., Salaspuro, M. (1992): Carbohydrate-deficient transferrin (CDT) in serum as a possible indicator of heavy drinking in young university students, Alcohol Clin Exp Res 16, 93-97.

38. Petren, $S$., Vesterberg, O. (1988): Concentration differences in isoforms of transferrin in blood from alcoholics during abuse and abstinence, Clin Chim Acta 175, 183-187.

39. Petren, S., Vesterberg, O. (1989): Separation of different forms of transferrin by isoelectric focusing to detect effects on the liver caused by xenobiotics, Electrophoresis 10, 600-604.

40. Poupon, R.E., Schellenberg, F., Nalpas, B., Weill, J. (1989): Assessment of the transferrin index in screening heavy drinkers from a general practice. Alcohol Clin Exp Res 13, 549-553.

41. Reisinger, P.W.M., Hochstraßer, K. (1989): The diagnosis of CSF fistulae on the basis of detection of B2-Transferrin by polyacrylamide gel electrophoresis and immunoblotting, $\mathrm{J}$ Clin Chem Clin Biochem 27, 169-172.

42. Reisinger, P.W.M., Soyka, M. (1990): Die Diagnose von Alkoholismus auf der Grundlage des Nachweises einer Transferrinvariante durch PolyacrylamidGelelektrophorese und Immunoblotting, Blutalkohol 27, 427-433.

43. Roine, R.P., Ylikahri, R., Koskinen, P. et al (1987): Effect of heavy weekend drinking on urinary dolichol levels, Alcohol 4, 509-511.

44. Roine, R.P. (1988): Effects of moderate drinking and alcohol abstinence on urinary dolichol levels, Alcohol 5, 229-231.

45. Roine, R.P. Eriksson, C.J.P. Ylikahri, R. et al (1989): Methanol as a marker of alcohol abuse, Alcohol Clin Exp Res 13, 172-175.

46. Rosman, A.S., Xin, Y., Galvin, K., Lasker, J.M., Baraona, E., Lieber, C.S (1991): Comparison of carbohydrate deficient transferrin and red blood cell cysteine as markers of alcohol consumption, Alcohol Clin Exp Res 15, 379. 47. Schacter, H. (1986): Biosynthetic controls that determine the branching and microheterogeneity of protein-bound oligosaccharides, Biochem Cell Biol 64, 163-181.

48. Schellenberg, F., Weill, J. (1987): Serum desialotransferrin in the detection of alcohol abuse: definition of a Tf index, Drug Alc Dep 19, 181-191.

49. Schellenberg, F., Weill, J. (1987): Increase in the desialylated forms of serum transferrin and alcohol consumption, Ann Biol Clin 45, 290-295.

50. Schellenberg, F., Benard, J.Y., LeGoff, A.M. et al (1989): Evaluation of carbohydrate-deficient transferrin compared with $\mathrm{Tf}$ and other markers of alcohol abuse, Alcohol Clin Exp Res 13, 605-610.

51. Sillanaukee, P., Seppä, K., Koivula, T. (1991): Effect of acetaldehyde on hemoglobine: $\mathrm{HbA1-ach}$ as a potential marker of heavy drinking. Alcohol 8 , 377-381.

52. Sillanaukee, P., Löf, K., Seppä, K., Koivula, T. (1993): CDT by anion.exchange chromatography followed by RIA as a marker of heavy drinking among men. Presented at a meeting with the Finnish Medical Association. Clinical Documentation CD-Tect, Kabi Pharmacia 1993.

53. Stamm, D. Hansert, E., Feuerlein, W. (1984): Excessive consumption of alcohol in men as a biological influence factor in clinical laboratory investigations, J Clin Chem Clin Biochem 22, 65-77.

54. Stamm, D., Hansert, E., Feuerlein, W. (1984): Detection and exclusion of alcoholism in men on the basis of clinical laboratory findings, $\mathrm{J}$ Clin Chem Clin Biochem 22, 79-96.

55. Stibler, H. (1977): Crossed immunoelectrofocusing for identification of normal and abnormal cerebrospinal fluid. A preliminary report J Neurol Sci 32, 331-336.

56. Stibler, H., Allgulander, C., Borg, S., Kjellin, K.G. (1978): Abnormal microheterogeneity of transferrin in serum and cerebrospinal fluid in alcoholism Acta Med S'cand 204, 49-56.

57. Stibler, H., Borg, S., Allgulander, C. (1979): Clinical significance of abnormal heterogeneity of transferrin in relation to alcohol consumption. Acta Med Scand 206, 275-281.

58. Stibler, H., Sydow, O., Borg, S. (1980): Quantitative estimation of ab normal microheterogeneity of serum transferrin in alcoholics, Pharmaco Biochem Behav 13, 47-51. 
59. Stibler, H., Borg, S., Allgulander, C. (1980): Abnormal heterogeneity of serum transferrin - A new diagnostic marker of alcoholism, Acta Psych Scand (Suppl) 286, 189-209.

60. Stibler, H., Borg, S. (1981): Evidence of a reduced sialic acid content in serum transferrin in male alcoholics, Alcohol Clin Exp Res 5, 545-549.

61. Stibler, H., Borg, S. (1982): Reduction of the sialic acid and galactose concentrations in erythrocyte membranes in alcoholics, Drug Alcohol Depend $10,85-98$.

62. Stibler, H., Borg, S., Joustra, M. (1986): Micro anion exchange chromatography of carbohydrate-deficient transferrin in serum in relation to alcoho consumption (Swedish Patent 8400587-5), Alcohol Clin Exp Res 10, 535-543. 63. Stibler, H., Borg. S. (1986): Carbohydrate decomposition of serum transferrin in alcoholic patients, Alcohol Clin Exp Res 10, 61-64.

64. Stibler, H., Borg, S. (1986): Glycoprotein sialyl-and galactosyl transferase activities in erythrocyte membranes in alcoholic patients and healthy controls, Drug Alcohol Depend 16, 331-340.

65. Stibler, H., Hultcrantz; R. (1987): Carbohydrate-deficient transferrin in serum in patients with liver diseases, Alcohol Clin Exp Res 11,468-473.

66. Stibler, H., Borg, S., Beckman, B. (1988): Transferrin phenotype and level of carbohydrate-deficient transferrin (CDT) in serum in healthy individuals, Alcohol Clin and Exp Res 12, 450-453.

67. Stibler, H. et al (1988): Carbohydrate-deficient transferrin (CDT) in serum as a marker of high alcohol consumption. In: Advances in the Biosciences, Pergamon Press 71, 353-357.

68. Stibler, H., Borg, S. (1988): The value of carbohydrate-deficient transferrin as a marker of high alcohol consumption. In: Biomedical and social aspects of alcohol and alcoholism. Editors: Kuriyama, K., Takada, A., Ishii, H.; Elsevier Science Publishers B.V., 503-506.

69. Stibler, H., Dahlgren, L., Borg, S. (1988): Carbohydrate-deficient transferrin (CDT) in serum in women with early alcohol addiction, Alcohol 5, 393-398.

70. Stibler, H., Borg, S. (1989): Glycoprotein glycosyltransferase activities in serum in alcohol abusing patients, Alcohol Alcoholism 24, 388.

71. Stibler, H., Jaeken, J. (1990): Carbohydrate deficient serum transferrin in a new systemic hereditary syndrome, Arch Dis Child 65, 107-111.

72. Stibler, H. (1991): Carbohydrate-deficient transferrin in serum: a new marker of potentially harmful alcohol consumption reviewed, Clin Chem 37, 20292037.

73. Stibler, H., Borg, S., Joustra, M. (1991): A modified method for the assay of carbohydrate-deficient transferrin (CDT) in serum, Alcohol Alcoholism (Suppl 1), 451-454.

74. Storey, E.L., Mack, U., Powell, L.W. et al (1985): Use of chromatofocusing to detect a transferrin variant in serum of alcoholic subjects, Clin Chem 31, $1543-1545$.
75. Storey, E.L., Anderson, G.J., Mack, U. et al (1987): Desialylated transferrin as a serological marker of chronic excessive alcohol ingestion, Lancet, 12921293.

76. Takase, S., Takada, A., Tsutsumi, M., Matsuda, Y. (1985): Biochemical markers of chronic alcoholism, Alcohol 2, 405-410.

77. Thomas, L.: Labor und Diagnose. Die medizinische Verlagsgesellschaft, 4. Auflage (1992)

78. Vesterberg, O., Petren, S., Schmidt, D. (1984): Increased concentrations of a transferrin variant after alcohol abuse, Clin Chim Acta 141, 33-39.

79. Weidinger, S., Schwarzfischer, F., Cleve, H. (1980): Classification of transferrin (Tf) subtypes by isoelectric focusing, Z Rechtsmed 85,255-261.

80. Weidinger, S., Cleve, H., Schwarzfischer, F., Postel, W., Weser, J., Görg, A (1984): Transferrin subtypes and variants in Germany; Further evidence for a Tf null allele, Hum Genet 66, 356-360.

81. Wittmann, S, Gilg, T., Dietz, H.G. et al (1992): Isopropanol- und Acetonspiegel im Serum nach präoperativer Flächendesinfektion mit isopropanolhaltigen Antiseptika, Blutalkohol 29, 326-335.

82. Clinical Documentation on CDTectTM by Kabi Pharmacia 1993

83. Kabi Pharmacia Diagnostics workshop on: CDT as a tool in the identification and treatment of alcohol related disease Clinical experiences with CDTect TM. 3.6.1993.

\section{Anschrift der Verfasser:}

Priv. Doz. Dr. med. Thomas Gilg'

Prof. Dr. rer. nat. Sebastian Weidinger ${ }^{2}$

Priv. Doz. Dr. med. Elisabeth Tutsch-Bauer'

Prof. Dr. rer. nat. Ludwig von Meyer ${ }^{1}$

Prv. Doz. Dr. med. Wilfried Peter Bieger ${ }^{2}$

Dr. med. Eberhard Josephi²,

jetzt: Institut für Blutgruppenforschung, Hohenzollernring 57, 50672 Köln

1 Institut für Rechtsmedizin der Ludwig-Maximilians-Universität München, Frauenlobstr. 7a, 80337 München

2 Medizinisch Immunologische Laboratorien, Mittererstr. 3. 80336 München 